\title{
Nutritional Risk Factors of Low Birth Weight Among poor Rural Mothers from Maharashtra, India.
}

\author{
Shobha Rao ${ }^{1}$ and Swati Raje ${ }^{2}$ \\ ${ }^{1}$ Society for Initiatives in Nutrition and Development, Pune 411 007, India. \\ ${ }^{2}$ Department of Community Medicine, MIMER Medical College, Talegaon Dabhade, Maharashtra, India.
}

Received: March 27, 2017; Accepted: June 25, 2017; Published: July 03, 2017

*Corresponding author: Dr. (Mrs.) Shobha Rao, Society for Initiatives in Nutrition and Development, 101, Vullari Apartment, Aundh I.T.I. Road, Pune - 411 007, Tel: 91 (020) 65001943; E-mail: raoari@yahoo.com

\begin{abstract}
Objective: Identifying nutritional risk factors associated with LBW is of critical importance to plan appropriate interventional programs for achievement in reduction of prevalence of LBW.

Method: Clinically normal full term ANC mothers registering within 20 weeks of gestation at a rural hospital in Maharashtra, India were enrolled $(\mathrm{n}=370)$. Their socioeconomic, demographic information, dietary consumption pattern and anthropometric measurements were recorded and were followed up till delivery.

Result: Most mothers had low education, were engaged in heavy work and had low family income. They were thin $(46.2 \pm 7.5 \mathrm{Kg})$, short $(150.8 \pm 6.1 \mathrm{~cm})$ and undernourished $\left(20.3 \pm 3.2 \mathrm{Kg} / \mathrm{m}^{2}\right)$. Mean birth weight of babies was $2568 \pm 305 \mathrm{~g}$ while the prevalence of low birth weight (LBW) was $41.9 \%$. Significant risk for LBW was seen for young ( $<20 \mathrm{yr}$ ) mothers (OR=2.21; CI: $1.1-4.3$ ), for those with previous abortion $(\mathrm{OR}=3.1$; $\mathrm{CI}: 1.7-5.4)$, for those with low $(<42.5 \mathrm{Kg})$ weight at registration $(\mathrm{OR}=1.8 ; \mathrm{CI}: 1.1-3.0)$ and for those with low $(<18.5 \mathrm{Kg} /$ $\mathrm{m}^{2}$ ) BMI (OR=1.8; CI: $\left.1.1-3.0\right)$. Significant risk was also observed for mothers with lower $(<1 / \mathrm{d})$ consumption of roti $(\mathrm{OR}=1.77$; $\mathrm{CI}$ : 1.0-3.1) and low ( $<1 \mathrm{cup} / \mathrm{wk}$ ) consumption of milk (OR=1.85; CI: 1.13.3 ) or milk products (OR=1.75; CI: 1.1- 2.7) and more importantly, it remained significant even after adjusting for the above maternal confounders.
\end{abstract}

Conclusion: Independent influence of nutritional factors i.e. low consumption of staple food and milk on risk of lbw assumes importance, as dietary modification offers the only modifiable avenue for improving birth weight in poor populations.

Keywords: Low Birth Weight; Maternal BMI; Maternal Dietary Consumption

\section{Introduction}

Eighty percent of all new born with Low Birth Weight (LBW) at term are born in Asia. High prevalence of low birth weight continues to be a major nutritional concern in many developing countries including India. Although poverty is an underlying cause, it is necessary to understand the factors of maternal environment; especially nutritional factors associated with risk of Low Birth Weight (LBW) so as to plan appropriate interventional activities. Maternal environment comprises of social, economic, demographic, nutritional and clinical variables which influence birth weight.

Among the socio economic variables family type, size, income and occupation affect food availability [1] and the work load of the mother, [2] while education of mother and her husband influences the important decisions [3] like seeking antenatal care during pregnancy that influence birth outcome. Similarly, certain demographic factors like early age at marriage and conception are known [4] to adversely affect the pregnancy outcome in many communities. In poor populations, the delayed age of menarche coupled with early age of marriage and subsequent conception, is more detrimental to pregnancy outcome [5]. There is substantial literature that addresses possible association of maternal age and pregnancy outcome [6]. Obstetric variables may even have direct influence on pregnancy outcome. For example, history of repeated abortions makes women more vulnerable for poor pregnancy outcome [7]. Studies have shown that spacing of less than 2 years between successive deliveries, adversely affects the pregnancy outcome in mothers from low socio-economic class. [8, 9, 10,11].

Maternal nutritional status is often an outcome of sociocultural settings in which the mother is brought up and is known to be one of the key determinants of pregnancy outcome. It is known that the populations where proportions of mothers with low levels of BMI are high are also the populations where several socio demographic factors have significant impact $[12,13]$ leading to high prevalence of LBW. The biological support that the mother gives to the child during its growth and development depends particularly upon maternal nutritional factors like her nutritional status, her nutrition through pregnancy and lactation and influence birth weight considerably.

Although the factors associated with birth weight are well studied, those associated with significant risk for LBW are not. In fact, the two issues are different as they have different 
implications. Issue of identifying nutritional factors associated with risk of LBW is of critical importance as achievement in reduction of prevalence of LBW will have multi factorial benefits such as reduction in mortality $[14,15]$ and morbidity, improvement in the growth rate of children etc. Present study attempts to examine whether nutritional factors have independent influence on risk of LBW among mothers from poor rural community of Maharashtra.

\section{Material And Methods}

Present study was a hospital based prospective study, carried out at Dr. Bhausaheb Sardesai Rural Hospital Talegaon, attached to MIMER medical college.

\section{Subjects}

The study population comprised of Anti Natal Care (ANC) cases who registered themselves at the Obstetrics and Gynechelogy out patients department of the hospital, for the first time within 20 weeks of gestation. Considering 35\% prevalence of low birth weight with $5 \%$ tolerance estimated sample size was 425 cases allowing for $15 \%$ loss to follow up. Clinically apparently normal ANC cases, within 18 to 40 years of age, were included in the study after obtaining their oral consent. Multiple pregnancies and cases with congenital anomalies or major illness for more than 3 weeks, were excluded from the study.

\section{Qualitative information}

Maternal socio economic and demographic information was collected on each enrolled woman at the time of registration using a structured questionnaire. It comprised of size of the family, monthly income, education and occupation of the mother as well as her husband. The demographic information about her age at menarche, marriage and at registration was also recorded. Similarly, obstetric information on variables like parity, spacing and previous abortions, if any, was recorded for each mother.

\section{Maternal nutritional status}

Maternal nutritional status was assessed using several anthropometric measurements. Maternal weight that reflects current nutritional status was measured using (up to $100 \mathrm{~g}$ ) digital weighing balance, while maternal height that reflects past nutritional status was measured (up to $0.1 \mathrm{~cm}$ ) using stediometer. Maternal head circumference which is believed to reflect maternal nutritional status when she was in utero was measured (up to $0.1 \mathrm{~cm}$ ) using non stretchable tape while body fat (\%) which is the reflection of mother's energy stores was recorded using body fat analyzer (HBF300, OMRON Corporation, Japan). Babies were measured at birth using digital weighing balance.

\section{Maternal dietary intake}

Dietary intake was assessed using pre tested Food Frequency Questionnaire (FFQ) to record consumption of various foods and their frequency in last one month. It covered total of 54 food items divided into 13 groups such as milk, milk products, cereals, lentils, legumes, vegetables, green leafy vegetables, fruits, non-vegetarian foods, snacks, bakery products etc. Amount of food intake was measured in terms of number of roties and in terms of serving spoons of standard size for other foods. Frequency of consumption in terms of once, twice or more in a day / week or month was also noted.

\section{Statistical methods}

Means of two groups were compared using 't' test while linearity in group means was tested using ANOVA. Logistic regression was done to estimate Odd Ratio (OR) for risk of low birth weight in higher category considering lower category as reference category for various risk factors. Statistical analysis of data thus collected was done using SPSS 19.0 version.

\section{Results}

In view of the persistent nature of high prevalence of LBW is a major public health problem in rural India, identifying factors associated with low birth weight is of vital importance for planning appropriate strategies to overcome it.

\section{Maternal socio economic variables}

Out of total 437 mothers registered for the study, 370 mothers completed the full gestational period of 37 weeks. Most mothers (56.5\%) had family size $<5$ and $87.8 \%$ of mothers had education only up to 10 th standard. They were either housewife (75.0\%) or were engaged in farming (17\%). Their husbands were also largely engaged in unskilled jobs $(47.1 \%)$ and almost all had low ( $<5000$ Rs) monthly income (Table 1). Trend in mean birth weight across sub categories of socio economic variables did not show significance (Fig.1).

\section{Maternal demographic variables}

The reported age at menarche was $>14 \mathrm{yr}$ in case of $71.2 \%$ mothers while a large proportion (47.4\%) had age at first conception less than 20 yrs. Thus, majority (73.5 \%) of mothers were young $(<25 \mathrm{yr})$ at registration (Table 1$)$. Among these demographic variables, age at menarche $(<14 \mathrm{yr})$ did not show association with mean birth weight but mother's age at registration showed significant positive association with mean birth weight (Fig1). Young mothers ( $<20$ years) at registration had babies with lowest birth weight $(2458 \pm 270$ g) and showed highest prevalence of LBW (61.4\%).

\section{Maternal obstetric variables}

Among the study population $41.6 \%$ were primy and among the multiparous mothers the interval between two successive pregnancies was $<2$ yr (Table 1) in case of 55.6\% mothers. Mean birth weight was lowest for primies (2507 \pm $252 \mathrm{~g})$ and increased significantly $(\mathrm{p}<0.001)$ with the parity of the mother (Fig 1). The prevalence of LBW among primies was considerably high (44.4\%).

\section{Maternal nutritional status}

Nutritional status of the mothers at registration was poor 

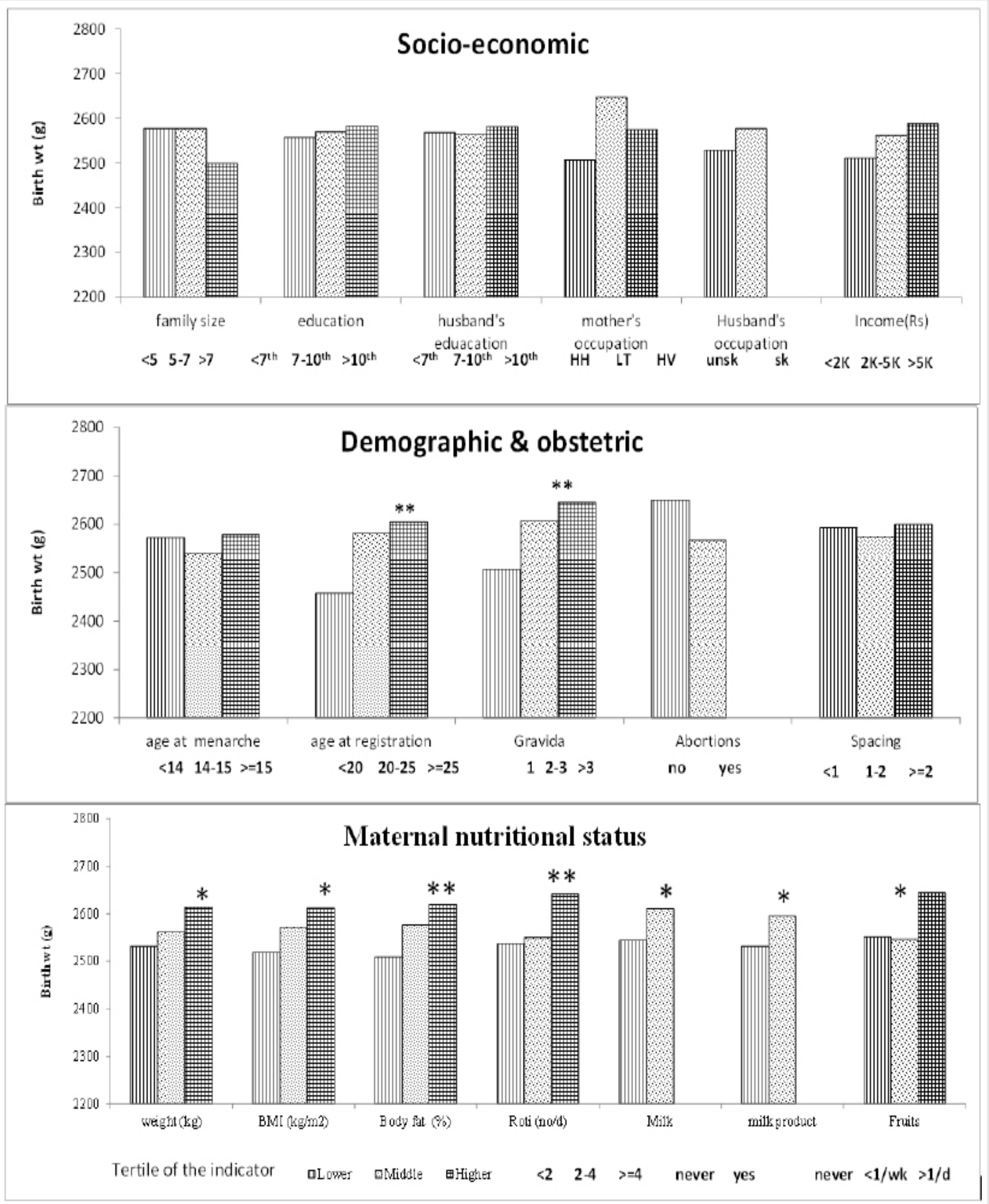

Figure 1: Mean birth weight (g) by levels of various factors of maternal environment.

BMI- Body mass index 
Table 1: Socioeconomic, demographic, obstetric and anthropometric measures of mothers

\begin{tabular}{|c|c|c|c|}
\hline Variable & Category & $\mathbf{N}$ & $\begin{array}{c}\text { Mean or } \\
\% \text { frequency }\end{array}$ \\
\hline \multirow{2}{*}{ Family Size } & $<5$ & 205 & 56.5 \\
\hline & $>=5$ & 158 & 43.5 \\
\hline \multirow{2}{*}{ Maternal education } & Up to $10^{\text {th }}$ std & 323 & 87.8 \\
\hline & $>10$ th std & 45 & 12.2 \\
\hline \multirow{2}{*}{ Husbands education } & Up to 10 th std & 307 & 83.7 \\
\hline & $>10$ th std & 60 & 16.3 \\
\hline \multirow{2}{*}{ Mothers occupation } & Light / Medium & 302 & 83.0 \\
\hline & Heavy & 62 & 17.0 \\
\hline \multirow{2}{*}{ Husbands occupation } & Unskilled & 81 & 22.4 \\
\hline & skilled & 280 & 77.6 \\
\hline \multirow{3}{*}{ Family income (Rs) } & $<2000$ & 55 & 15.3 \\
\hline & $2000-5000$ & 162 & 45.0 \\
\hline & $>5000$ & 143 & 39.7 \\
\hline \multirow{2}{*}{ Parity } & Primy & 153 & 41.6 \\
\hline & $>1$ & 215 & 58.4 \\
\hline \multirow{2}{*}{ Spacing (yr) } & $<2$ & 119 & 55.6 \\
\hline & $>=2$ & 95 & 44.4 \\
\hline \multirow{2}{*}{ No. of abortions } & Nil & 111 & 51.9 \\
\hline & $>=1$ & 103 & 48.5 \\
\hline \multirow{3}{*}{ Age at menarche (yr) } & $<14$ & 105 & 28.8 \\
\hline & $14-15$ & 141 & 38.5 \\
\hline & $>=15$ & 119 & 32.7 \\
\hline \multirow[t]{3}{*}{ Age at registration (yr) } & $<20$ & 57 & 15.4 \\
\hline & $20-25$ & 215 & 58.1 \\
\hline & $>=25$ & 98 & 26.5 \\
\hline
\end{tabular}

(Table 2). Mothers were thin and the mean maternal weight was lower $(46.2 \pm 7.5 \mathrm{Kg})$ suggesting that current nutritional status was poor. This was also true with regard to maternal height showing a smaller mean height $(150.9 \pm 6.1 \mathrm{~cm})$ indicating that they had experienced malnutrition in the past. Consequently, maternal undernutrition was reflected in the lower mean BMI $\left(20.3 \pm 3.2 \mathrm{Kg} / \mathrm{m}^{2}\right)$. Further, almost $9.8 \%$ of mothers were below $38 \mathrm{~kg}$ and $8.6 \%$ of mothers were below $145 \mathrm{~cm}$ for height, which are risk cut offs for low birth weight. Almost $32.0 \%$ women were under nourished as their BMI was below $18.5 \mathrm{~kg} / \mathrm{m}^{2}$.

The mean birth weight was only $2568 \pm 305$ g owing to the fact that large proportion of mothers was undernourished. The lowest birth weight was $1700 \mathrm{~g}$ while the highest birth weight was $3750 \mathrm{~g}$. The prevalence of LBW was $41.9 \%$ and the mean birth weight of normal babies was only $2731 \pm 289 \mathrm{~g}$.

All the three indicators of mother's nutritional status showed significant positive association with birth weight indicating that poorer the nutritional status lower was the birth weight. Thus, mean birth weight of the babies born to mothers in the lowest tertile of weight $(2532 \pm 313 \mathrm{~g})$, or BMI $(2518 \pm 308 \mathrm{~g})$, or body fat $(2509 \pm 292 \mathrm{~g})$ was lowest (Fig.1) with highest prevalence of LBW $(50.0 \%, 50.8 \%$ and $48.7 \%$ respectively ).

\begin{tabular}{|c|c|c|}
\hline \multicolumn{3}{|c|}{ Table 2: Maternal anthropometric measures (mean $\pm \mathrm{sd}$ ) } \\
\hline Variable & $\mathrm{N}$ & Mean \pm sd \\
\hline Weight (kg) & 368 & $46.2 \pm 7.5$ \\
\hline Height (cm) & 342 & $151.0 \pm 5.9$ \\
\hline BMI (kg/m2) & 359 & $20.3 \pm 3.2$ \\
\hline Body fat (\%) & 343 & $24.7 \pm 6.4$ \\
\hline Below risk cut off for weight & & \\
\hline i.e. \% below 38 Kg & 36 & 9.8 \\
\hline Below risk cut off for height & & \\
\hline i.e. \% below $145 \mathrm{~cm}$ & 31 & 8.6 \\
\hline $\begin{array}{c}\text { Undernutrition } \\
\text { i.e. BMI \% below } 18.5 \mathrm{Kg} / \mathrm{m} 2\end{array}$ & 115 & 32 \\
\hline BMI - Body Mass Index & & \\
\hline
\end{tabular}

\section{Maternal dietary intake}

Majority of mothers were vegetarian and Roti or Bhakari (bread made from wheat or sorghum), was a major food item consumed at all the three meals and contributed more than $75 \%$ of day's energy intake. Rice was mostly included only at dinner time. Almost half of the mothers (44.8\%) consumed dal on alternate days. Only $35 \%$ mothers had one serving or more of vegetables everyday and 16\% included green leafy vegetables in their daily diet. Their diets clearly lacked variety. Intake of milk was very low and two third (66.4\%) mothers never drank milk. Nearly $42 \%$ mothers had fruits daily which included seasonal fruits like banana, oranges, guava, grapes and berries and apple.

We examined mean birth weight by levels of consumption of all 13 food groups but found significant trends only for specific foods like roti, milk and milk products. Mothers having lower consumption of roti, which was their staple food, had babies with significantly lower birth weight $(2537 \pm 283 \mathrm{~g})$ and showed higher prevalence $(47.0 \%)$ of LBW. Significantly low birth weight of babies was also observed (Fig 1) among mothers who never consumed milk (2544 $\pm 315 \mathrm{~g})$ or milk products $(2532 \pm 299 \mathrm{~g})$ showing high prevalence of LBW too (46.4\% and $49.4 \%$ respectively).

\section{Maternal environment and risk of LBW}

We examined various maternal factors for risk of LBW (OR). Among socio economic factors family income showed marginal $(p=0.07)$ significance while among the demographic variables, younger maternal age at registration was a significant risk factor (Table 3) for delivering LBW (OR = 2.21; 
CI: 1.1-4.3; p<0.05). Among the obstetric variables parity did not confer risk for LBW but previous history of abortion was a significant risk factor for LBW. Thus, mothers who had previous abortion had significantly higher risk (OR=3.1; CI: 1.7-5.4; $\mathrm{p}<0.05$ ) for delivering LBW baby (Table 3 ).

Table 3: Factors of maternal environment and OR for risk of LBW

\begin{tabular}{|c|c|c|c|c|}
\hline \multirow{2}{*}{$\begin{array}{c}\text { Variable } \\
\text { Family income (Rs) }\end{array}$} & Categories & \multicolumn{3}{|c|}{ OR (CI) for lbw by categories } \\
\hline & $<2 \mathrm{k} \quad 2 \mathrm{k}-5 \mathrm{k} \quad>=5 \mathrm{k}$ & $1.78(0.95-3.3)$ & 1.22 & 1.0 \\
\hline Age (yr) at menarche & $<14 \quad 14-15 \quad \geq 15$ & 1.4 & 0.96 & 1.0 \\
\hline Age (yr) at registration & $<20 \quad 20-25 \quad \geq 25$ & $2.21^{*}(1.1-4.3)$ & 0.81 & 1.0 \\
\hline Previous abortions & No & $3.1^{*}(1.7-5.4)$ & 1.0 & \\
\hline $\operatorname{BMI}\left(\mathrm{Kg} / \mathrm{m}^{2}\right)$ & $<18.518 .5-21.1 \geq 21.1$ & $1.80 *(1.1-3.0)$ & 1.14 & 1.0 \\
\hline Consumption of Roti (no/d) & $2-4$ & $1.77^{*}(1.0-3.1)$ & 1.6 & 1.0 \\
\hline Milk (cup/d) & $<1 /$ wk $1 /$ wk to $1 / \mathrm{d} \geq 1 / \mathrm{d}$ & $1.85 *(1.1-3.3)$ & $1.37(0.63-3.0)$ & 1.0 \\
\hline Milk product & $<1 / w k \quad \geq 1 / w k$ & $1.75 *(1.1-2.7)$ & 1.0 & \\
\hline
\end{tabular}

BMI - Body mass index; Wt - Maternal weight

OR (CI) - Odds ratio ( $95 \%$ confidence interval)

Maternal nutritional status is a known determinant of birth weight and a significant risk for LBW was indeed observed for mothers with poor maternal nutritional status. Thus, significant $(\mathrm{p}<0.05)$ risk for LBW was seen for low $(<42.0$ $\mathrm{Kg}$ ) maternal weight ( $\mathrm{OR}=1.87, \mathrm{CI}: 1.1-3.1)$ as well as for low $\left(<18.5 \mathrm{Kg} / \mathrm{m}^{2}\right)$ BMI $(\mathrm{OR}=1.83$, CI: 1.1-3.0). No associations were seen for maternal height or head circumference. Poor maternal nutritional intake during pregnancy contributes to low birth weight and accordingly we observed that inadequate consumption of specific foods was associated with significant risk for LBW. Thus, mothers who never consumed milk or milk products had significant $(\mathrm{p}<0.05)$ risk $(\mathrm{OR}=1.62$, CI: 1.0 2.6 and $\mathrm{OR}=1.75, \mathrm{CI}$ : 1.0-2.7 respectively) for LBW (Table 3). It was also true in case of low consumption of a staple food viz., roti $(\mathrm{OR}=1.77, \mathrm{CI}: 1.0-3.1, \mathrm{p}<0.05)$. More importantly, the ORs for roti and milk remained significant even after adjusting for these maternal cofactors (maternal age, maternal weight and previous history of abortion) indicating the independent effect of maternal consumption of these specific foods i.e. roti and milk on the risk of LBW (Table 4).

\section{Discussion}

Poor maternal nutrition resulting in Low Birth Weight (LBW) remains single most important cause of infant mortality and morbidity in developing world. The factors responsible for LBW range from socio demographic to genetic, illustrating a wide spectrum of underlying causes. Several socioeconomic, demographic, obstetric and dietary factors have been shown to influence birth weight $[16,17,18,19]$ but only few researchers have examined their association with risk of LBW [20, 21]. In order to have effective strategies to combat the problem of LBW, it may be necessary to look into the nutritional risk factors. Our observations highlight that maternal diet is a major factor of the maternal environment and that consumption of staple food like roti and a functional food like milk, show significant association with risk of LBW even after adjusting for all other maternal cofactors.

Although most studies identify income as one of the determinants for LBW, only few examined its association with risk of LBW using broad categories as below and above poverty line [22, 23]. We observed marginal risk associated with family income below Rs.2000 and is in confirmation with studies from Bangladesh, [24] and Pakistan [25].

Adverse influence of demographic variables like early age at marriage and early age at conception on reproductive health has been reported $[26,27,28]$. Similarly, devastating effects of early conception in terms of increased risks for pregnancy wastage (stillbirths \& abortion) and premature delivery are reported among adolescent rural Indian undernourished girls [5] but are not reported for risk of LBW. We observed that mothers with younger age $(<20 \mathrm{yr})$ at registration had 2.21 times higher risk for LBW compared to those who were aged more than $25 \mathrm{yr}$.

Importance of maternal nutritional status is unquestionable in the context of low birth weight. In fact, the countries where high proportions of LBW are seen are also the countries where women have low body mass index, indicating poor maternal nutritional status which is a major determinant of LBW. We observed that mothers in the lowest tertile of maternal weight $(<42.5 \mathrm{Kg})$ or maternal BMI $\left(<18.5 \mathrm{Kg} / \mathrm{m}^{2}\right)$ indicated 1.8 times higher risk of LBW compared to their counterparts. This is in confirmation with a study [10] reporting four times risk of LBW for mothers with weight $<45 \mathrm{Kg}$. from rural Maharashtra. A study from Bangladesh [29] also reports $43 \mathrm{~kg}$ and 19kg/ $\mathrm{m}^{2}$ as respective cut offs for maternal weight and BMI for predicting the risk of LBW. 
Table 4: Risk (OR) for LBW associated with consumption level of Roti and milk after adjusting for several maternal cofactors

\begin{tabular}{|c|c|c|c|c|c|}
\hline \multirow[t]{2}{*}{ Food item } & \multirow{2}{*}{$\begin{array}{l}\text { Frequency of } \\
\text { consumption }\end{array}$} & \multirow{2}{*}{$\begin{array}{l}\text { Unadjusted } \\
\text { OR }\end{array}$} & \multicolumn{3}{|c|}{ OR adjusted ${ }^{+}$for maternal } \\
\hline & & & age (yr) & abortion & weight (Kg) \\
\hline \multirow[t]{3}{*}{ Roti consumption no./d } & $<2$ & $\begin{array}{c}1.77 \\
(1.0-3.0)\end{array}$ & $\begin{array}{l}1.86 \\
(1.0-3.3)\end{array}$ & $\begin{array}{c}1.98 \\
(1.1-3.4)\end{array}$ & $\begin{array}{c}1.84 \\
(1.0-3.2)\end{array}$ \\
\hline & $2-4$ & $\begin{array}{c}1.61 \\
(0 . .89-2.9)\end{array}$ & $\begin{array}{l}1.75 \\
\quad(0.96-3.2)\end{array}$ & $\begin{array}{c}1.84 \\
(1.0-3.4)\end{array}$ & $\begin{array}{c}1.66 \\
(0.9-3.1)\end{array}$ \\
\hline & $>=4$ & 1.0 & 1.0 & 1.0 & 1.0 \\
\hline \multirow[t]{2}{*}{$\begin{array}{l}\text { Milk } \\
\text { consumption }\end{array}$} & Never & $\begin{array}{c}1.77 \\
(1.1-2.8)\end{array}$ & $\begin{array}{c}1.85 \\
(1.2-2.9)\end{array}$ & $\begin{array}{c}1.91 \\
(1.2-2.9)\end{array}$ & $\begin{array}{c}1.92 \\
(1.1-2.8)\end{array}$ \\
\hline & Yes & 1.0 & 1.0 & 1.0 & 1.0 \\
\hline
\end{tabular}

+ Adjustment done by adding sequentially each maternal cofactor

Although short maternal height or smaller head circumference have been shown to be associated with birth weight by other researchers [30] they did not turn out to be risk factors for LBW. Similarly, body fat was associated with mean birth weight but did not prove to be a risk factor for LBW. Finally, our observation that low consumption (< 1 /d) of roti shows 1.77 times high risk for LBW while not consuming milk during gestation shows 1.62 times higher risk assumes significance as dietary modification offers the modifiable and feasible avenue for improving birth weight in poor populations. Further, the risks became significant after adjusting for several cofactors of maternal environment, indicating independent effect of these specific foods. Low milk consumption (less than $250 \mathrm{ml} /$ day) is shown to be associated with low birth weight among Canadian [31] and Danish women [32]. Review of studies published in the recent decade also reports a significant positive association between maternal milk consumption and fetal growth as well as infant birth weight and suggests the importance of including some milk and dairy in the maternal diet essentially as a source of protein and other valuable nutrients $[33,34]$. Our observation not only supports above findings but also indicates that providing one cup of milk per day to undernourished mother from rural India could be a simple feasible and possible food based intervention for improving the birth weight.

In conclusion, maternal environment comprises of several socio economic and demographic factors besides her nutritional status that influence birth weight. The fact that associations of some of these factors with mean birth weight did not necessarily imply associations with risk of LBW, is in line with the report that in South Asia during last few decades, there has been marginal improvement (52 to $126 \mathrm{~g}$ ) in birth weight but not in the prevalence of LBW [35]. Identifying nutritional risk factors associated with LBW in poor populations is therefore of vital importance for reducing its prevalence. Most importantly, our observation that specific foods like roti and milk have independent effect underscores the importance of maternal diet. These food items being items from their daily food basket, opens an avenue for planning food based interventions for rural Indian mothers that are likely to have higher degree of compliance. Secondly, in view of the recent report [36] imparting nutrition education for dietary modification appears promising approach to bring about behavioural change resulting in sustainable improvement in the overall quality of the maternal diet. In contrast, improving maternal nutritional status of young rural mothers or increasing their age at marriage for preventing early conception are difficult propositions to achieve in a short period of time due to socio-cultural factors. Finally, different populations and in different settings may indicate different pivotal factors and foods for their associations with risk of LBW. Based on such pivotal factors, research must address to develop a simple screening tool which can be used by a lowest level health worker for identifying mothers at risk. Our findings therefore, have wider implications for similar rural settings especially from other developing countries in Asia

\section{Acknowledgements}

We acknowledge the support of the management of MIMER medical college and Dr. (Mrs.) B. Patnaik Professor and Head Community medicine, MIMER Medical College for giving full support to do this study in the department. Special thanks to Dr. Sushma Sharma, Asso. Professor, Obstetrics and Gynaecology, MIMER medical college, who helped to record the clinical findings of the study population.

\section{References}

1. Nenko I, Hayward AD, Lummaa V. The effect of socio-economic status and food availability on first birth interval in a pre-industrial human population. Proc R Soc B. 2014;281(1775):20132319. doi: 10.1098/ rspb.2013.2319

2. Barker M, Chorghade G, Crozier S, Leary S and Caroline Fall. Socioeconomic factors, lifestyle and gender differences in body mass index in rural India J Nutr. 2006;136(12):3062-3068.

3. Acharya, Bell JS, Simkhada P, van Teijlingen ER, Regmi PR. Women's 
autonomy in household decision-making: a demographic study in Nepal Reproductive Health. 2010; 7:15. doi: 10.1186/1742-4755-7-15

4. Aras RY. Is maternal age risk factor for low birth weight? Arch Med Health Sci 2013;1(1):33-37.

5. Rao S, Gokhale M, Joshi S and Kanade A. Early life undernutrition and adolescent pregnancy outcome in rural India. Ann Hum Biol. 2010;37(4):475-487. doi: 10.3109/03014460903434941

6. Meis PJ, Goldenverg RL, Mercer B, Morwad A, Das A, MC Nellis D, et al. The pre term prediction study: significance of vaginal infections. National Institute of child health and human development. Maternal - Fetal Medicine Units Network. Am J Obstet Gynecol. 1995;173(4):7231-7235

7. Motghare DD, Frederick S Vaz, Pawaskar AM, Kulkarni MS. Maternal determinants of intrauterine growth restriction in Goa, India: a casecontrol study. Gjmedph org. 2014;3(1).

8. Agustin Conde-Agudelo, Anyeli Rosas-Bermu' dez, Ana Cecilia Kafury Goeta. Birth spacing and risk of adverse perinatal outcomes A metaanalysis. JAMA. 2006;295(15):1809-1823.

9. DaVanzo J, Hale L, Razzaque A and Rahman M. Effects of interpregnancy interval and outcome of the preceding pregnancy on pregnancy outcomes in Matlab, Bangladesh. BJOG. 2007;114(9):10791087. doi: 10.1111/j.1471-0528.2007.01338.x

10. Deshpande JD, Deepak Phalke, D Peeyuusha, Bhatt Sushen. Maternal risk factors for low birth weight neonates: a hospital based casecontrol study in rural area of western Maharashtra, India. National Journal of Community Medicine. 2011;2(3):394-398.

11. Thomre PS, Borle, JD Naik, SS Rajderkar. Maternal risk factors determining birth weight of newborns: A tertiary care hospital based study. International Journal of Recent Trends in Science and Technology. 2012;5(1):3-8.

12. Neuman M, FinlayJE, Smith GD, and Subramanian SV. The poor stay thinner: stable socioeconomic gradients in BMI among women in lower and middle-income countries. Am J Clin Nutr. 2011;94(5):13481357. doi: 10.3945/ajcn.111.018127

13. Chockalingam R, Raghavan R, Agrawal J, George Warren, Hor Yan, Angel Lai, et al. Understanding Geographic Variations in BMI in India. 2011. CSD Working Papers No. 11-13. Center for social development Washington university. St Louis.

14. Bang AT, Bang RA, Baitule S, Deshmukh M, Reddy MH. Burden of Morbidities and the Unmet Need For Health Care in Rural NeonatesA Prospective Observational Study in Gadchiroli, India. Indian Pediatrics. 2001;38(9):952-965.

15. Niswade A, Zodpey SP, Ughade S, Bangdiwala SI. Neonatal Morbidity and Mortality in Tribal and Rural Communities in Central India Indian Journal of Community Medicine. 2011;36(2):150-158. doi: 10.4103/0970-0218.84137

16. A Matin, SK Azimul, AKM Matiur, S Shamianaz, JH Shabnam, T Islam. Maternal Socioeconomic and Nutritional Determinants of Low Birth Weight in Urban area of Bangladesh. J Dhaka Med Coll. 2008;17(2):8387.

17. Jawarkar AR, Lokare PO, Dore S. Study of Socio - Demographic and Maternal Determinants Influencing Birth weight. J MGIMS. 2012;17(ii):28-33.

18. Kashif Shahnawaz, Sanjay Kumar Choudhary, Gautam Sarker, Palash Das, Ranabir Pal, Laxman Kumar. Association between Maternal Socio-Demographic Factors and Low Birth Weight Newborn in rural area of Bihar. South East Asia Journal of Public Health. 2014;4(1):30-
34.

19. Muthayya S. Maternal nutrition \& low birth weight- what is really important? Indian Journal of Med Res. 2009;130(5):600-608.

20. Deshmukh JS, Motghare DD, Zodpey SP, Wadhva SK. Low birth weight and associate maternal factors in an urban area. Indian Pediatr. 1998;35(1):33-36.

21. Hirve SS and Ganatra BR. Determinants of low birth weight: A community based prospective cohort study. Indian Pediatr. 1994;31(10):1221-1225.

22. Aparajita Dasgupta, Rivu Basu. Determinants of low birth weight in a Block of Hooghly, West Bengal: A multivariate analysis. Int J Biol Med Res. 2011;2(4):838-842.

23. Mumbare SS, Maindarkar G, Darade R, Yenge S, Tolani MK, Patole K. Maternal Risk Factors Associated with Term Low Birth weight Neonates: A Matched-Pair Case Control Study Indian Pediatr. 2012;49(1):25-28.

24.JC Das, Nibedita Paul. Association of Maternal Socio Biological factors with Birth Weight of Newborn Baby. JCMCTA. 2008;19(1):37-42.

25. Badshah S, Linda Mason, Kenneth Mc Kelvie, Roger Payne, Paulo JG Lisboa. Risk factors for low birth weight in the public-hospitals at Peshawar, NWFP-Pakistan. BMC Public Health. 2008,8:197. doi: 10.1186/1471-2458-8-197

26. Prakasam CP. Mother's reproduction and pregnancy loss in a rural set up. Demography India.1993:22(2):155-68.

27. Thame M, Wilks RJ, McFarlane-Anderson N, Bennett FI, Forrester TE. Relationship between maternal nutritional status and infant's weight and body proportions at birth. Eur J Clin Nutr. 1997;51(3):134-138.

28. Lenders CM, McElrath TF, Scholl TO. Nutrition in adolescent pregnancy. Curr Opin Pediatr. 2000;12(3):291-296.

29. Nahar S, Mascie-Taylor CGN and Begum HA. Maternal anthropometry as a predictor of birth weight. Public Health Nutr. 2007;10(9):965970.

30. Hassan Ne, AH Shalaan, SA El-Masry. Relationship between maternal characteristics and neonatal birth size in Egypt. Eastern Mediterranean Health Journal. Alexandria. 2011;17(4):281-289.

31. Mannion Cynthia A, Katherine Gray-Donald, Koski Kristine G. Association of low intake of milk and vitamin D during pregnancy with decreased birth weight. CMAJ. 2006;174(9):1273-1277.

32. Olsen SF, Halldorsson TI, Willett WC, Knudsen VK, Gillman MW, Mikkelsen TB, et al. Milk consumption during pregnancy is associated with increased infant size at birth: prospective cohort study. Am J Clin Nutr. 2007;86(41):1104-1110.

33. Brantsæte AL, Olafsdottir AS, Forsum E, Olsen SF, Thorsdottir I. Does milk and dairy consumption during pregnancy influence fetal growth and infant birth weight? A systematic literature review. Food \& Nutrition Research. 2012;56. doi: 10.3402/fnr.v56i0.20050

34.Imdad A and Bhutta ZA. Effects of calcium supplementation during pregnancy on maternal, fetal and birth outcomes. Paediatr Perinat Epidemiol. 2012;26(1):S138-S152. doi: 10.1111/j.13653016.2012.01274.x

35. Sachdev HPS. Low birth weight in South Asia. Int J Diab Dev Countries. 2001;21:13-31.

36. Rao S, Joshi S, Bhide P, Puranik B, Kanade A. Social dimensions related to anaemia among women of childbearing age from rural India. Public Health Nutrition. 2011;14(2):365-372. doi: 10.1017/ S1368980010002776 